\title{
Wind Profiling with an Eye-Safe Coherent Doppler Lidar System: Comparison with Radiosondes and VHF Radar
}

\author{
Shoken ISHII, Kohei MIZUTANI, Tetsuo AOKI, Masahiko SASANO ${ }^{1}$, \\ Yasuhiro MURAYAMA, Toshikazu ITABE
}

National Institute of Information and Communications Technology, Koganei, JAPAN

and

Kazuhiro ASAI

Tohoku Institute of Technology, Sendai, JAPAN

(Manuscript received 9 November 2004, in final form 5 September 2005)

\begin{abstract}
An eye-safe airborne coherent Doppler lidar system has been developed at the National Institute of Information and Communications Technology (NICT). This system can also be used at ground level and ground-based experiments were made to evaluate the system performance at the NICT Wakkanai radio observatory. The obtained wind profiles were compared with those measured by radiosondes launched at the Wakkanai local meteorological observatory, and by a VHFR system installed by NICT near the Wakkanai airport. Although the volume measured by the coherent Doppler lidar system differed spatially and temporally from those by the radiosonde and the NICT VHF radar system, the wind profiles observed by the coherent Doppler lidar system agreed well with those observed by other instruments. The wind velocities obtained through the full correlation analysis of the VHF radar system were a little smaller than those from the coherent Doppler lidar system, which is consistent with previous statistical results for the VHF radar system. The ground-based results showed that the standard deviations of wind velocity estimates in the laser pulse accumulation seemed to approach a constant value under the real atmospheric conditions, and that the lower limit of the signal-to-noise ratio for the reliable estimate of the wind velocity decreases with the laser pulse accumulation. The ground-based experiments showed that the coherent Doppler lidar system is a reliable system for wind-related research.
\end{abstract}

\section{Introduction}

Wind profile is fundamental in many atmospheric issues, such as numerical weather prediction, global climate modeling, atmospheric transport of many substances, and investiga-

Corresponding author: Shoken Ishii, National Institute of Information and Communications Technology, 4-2-1 Nukuikitamachi, Koganei-shi, Tokyo 184-8795, Japan.

E-mail: sishii@nict.go.jp

1 Present affiliation: National Maritime Research Institute.

(C) 2005, Meteorological Society of Japan tion of local and mesoscale weather phenomena. For such purposes, we need to obtain three-dimensional wind distributions. Radiosondes and wind-profiler radar systems are typically used to measure wind profiles. Most weather stations and wind-profiler radar sites are located in developed countries, though, and weather stations at sea are very sparsely distributed. A global observation system for measuring the three-dimensional distribution of winds is urgently needed. A compact Doppler lidar system can be designed so that it is suitable for use as a mobile system, as an airborne 
system, and probably as a space-borne system. Several groups have investigated the impact of global winds on numerical weather prediction by using a space-borne Doppler lidar system (Rohaly and Krishinamurti 1993; Baker et al. 1995; Atlas 1997). Ground-based coherent and incoherent Doppler lidar systems (e.g., Kavaya et al. 1989; Shibata et al. 1991; Post and Cupp 1992; Henderson et al. 1993; Souprayen et al. 1999; Cohn et al. 2000; Gentry et al. 2000; Flesia et al. 2000; Grund et al. 2001), and airborne coherent Doppler lidar systems (Bilbro et al. 1984; Targ et al. 1996; Rothermel et al. 1998; Werner et al. 2001) have been developed for wind measurements. The recent application of the diode-laser-pumped eye-safe solid-state laser has expanded the capability of the more compact and reliable Doppler lidar system (Henderson and Ota 1997).

In light of these circumstances, the National Institute of Information and Communications Technology (NICT, Koganei Tokyo) has studied an eye-safe airborne coherent Doppler lidar (CDL) system. The first objective in this development is to demonstrate the feasibility of using a CDL system from a moving platform, the second objective is to devise an algorithm for measuring wind velocity and direction, and the third objective is to realize a precursor system for a space-borne coherent Doppler lidar system for installation in the International Space Station (Itabe et al. 2001). Ground-based experiments with the coherent Doppler lidar system have been performed to confirm the system operation capabilities, and the developed algorithm. The initial ground-based experiment was conducted at NICT from June 4 to 20, 2001. In the experiment, the signal was digitized with a digital oscilloscope and transferred to a computer, and the data acquisition rate of only $4 \mathrm{~Hz}$ was possible. The wind profiles obtained by the CDL system were compared with the wind profiles measured by a pulsed Doppler radar system (wind profiler) installed at NICT and the results obtained with each system were fairly consistent (Ishii et al. 2002). Since it took about 20 minutes to obtain a wind profile because of slow signal processing, the temporal resolution of this CDL system was quite low. A faster signal-processing system was introduced after the initial ground-based experiment and was used in the system we discuss in this pa- per. Wind profiles were obtained with the improved CDL system every 3 to 5 minutes on September 3 and 4, 2002 at the NICT Wakkanai radio observatory $\left(45.39^{\circ} \mathrm{N}, 141.69^{\circ} \mathrm{E}\right)$. We compared wind profiles observed by the CDL system with those observed through radiosondes and the NICT VHF radar system (the VHFR system). The excellent results obtained through these experiments are discussed below.

\section{Measurement site and coherent Doppler lidar system}

\subsection{Measurement site and synoptic map}

The NICT Wakkanai radio observatory (WRO) $\left(45.39^{\circ} \mathrm{N}, 141.69^{\circ} \mathrm{E}\right)$ is about $2 \mathrm{~km}$ south-southeast of the Wakkanai local meteorological observatory (WLMO) $\left(45.42^{\circ} \mathrm{N}\right.$, $141.68^{\circ} \mathrm{E}$ ), and about $11 \mathrm{~km}$ west-northwest of the NICT VHF radar site (VHFRS) $\left(45.36^{\circ} \mathrm{N}\right.$, $141.85^{\circ} \mathrm{E}$ ) [Fig. 1(a)]. The Wakkanai local meteorological observatory launches radiosondes to measure pressure, wind, temperature, and humidity at 9 JST (JST $=\mathrm{UTC}+9$ hours) and 21 JST and for wind profiling at 3 JST and 15 JST. The VHFR system measures wind profiles at altitudes of 1 to $13 \mathrm{~km}$ with temporal resolution of $5 \mathrm{~min}$ and height resolution of $600 \mathrm{~m}$ (Igarashi et al. 2000). The NICT Wakkanai radio observatory, the NICT VHF radar site, and the Wakkanai local meteorological observatory are located along the shoreline. There are no high mountains around the NICT Wakkanai radio observatory that could block or disturb the airflow.

Figure 1(b) shows a 500-hPa synoptic map obtained at 9 JST on September 4. An extratropical low-pressure system which developed from Typhoon 0215 was located in the northeast of Hokkaido Island. The cyclonic flow of the low-pressure system brought winds from the west or west-northwest for a couple of days.

\subsection{Principle of coherent Doppler lidar system and analysis}

A block diagram of the CDL system (manufactured by Coherent Technologies Inc.) is shown in Fig. 2. The specifications of the system are listed in Table 1 . The principal components are a master oscillator (MO), a high-power Q-switched slave oscillator (SO), a telescope, a scanning device, two heterodyne 

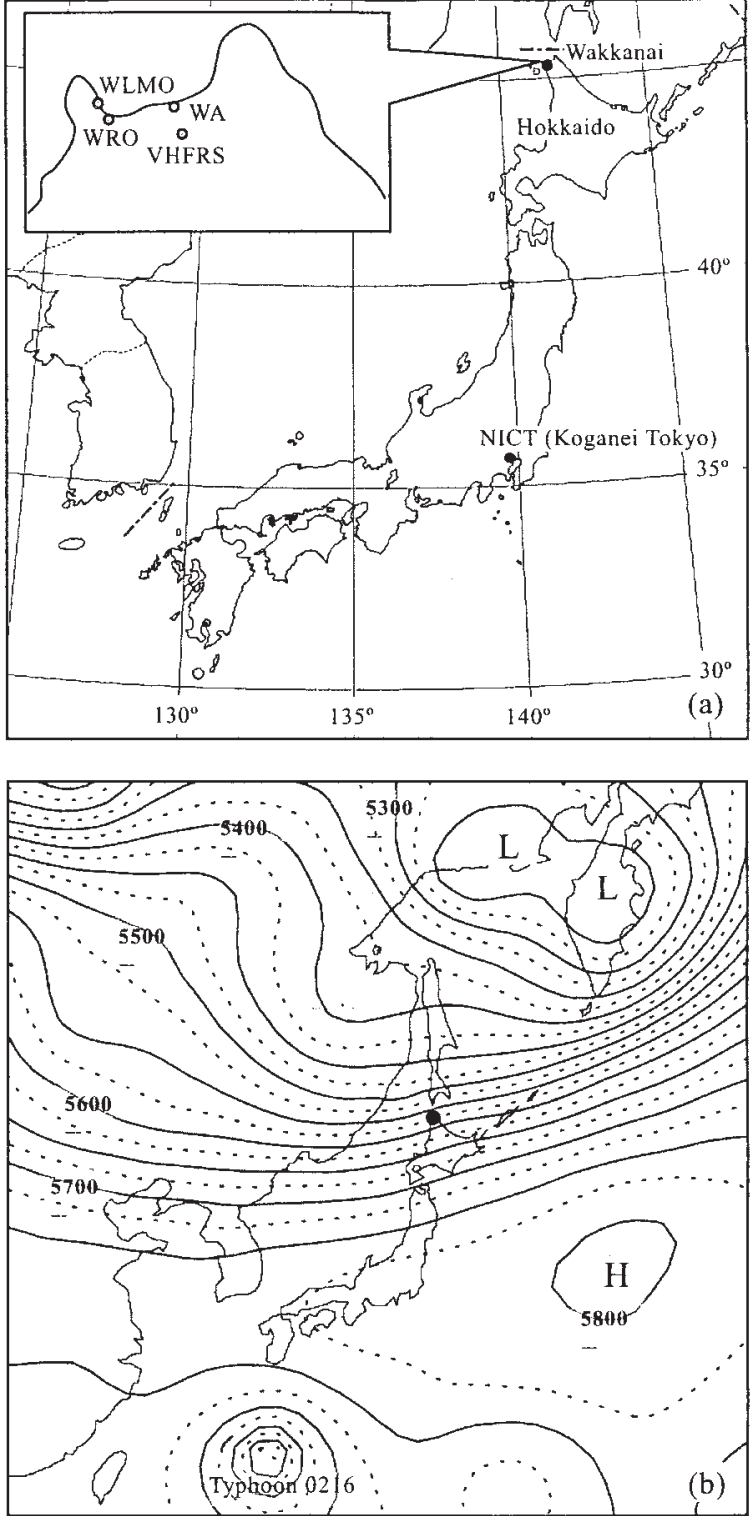

Fig. 1. (a) Maps showing the location of the Wakkanai area: NICT Wakkanai radio observatory (WRO), NICT VHF radar site (VHFRS), Wakkanai local meteorological observatory (WLMO), and Wakkanai airport (WA). (b) 500$\mathrm{hPa}$ synoptic map at 9:00 JST on September 4, 2002. Contour line is the geopotential height.

detectors, and signal processing equipment. The MO is an eye-safe continuous wave diode-laser-pumped single-longitudinal-mode Tm:YAG laser emitting at a wavelength of

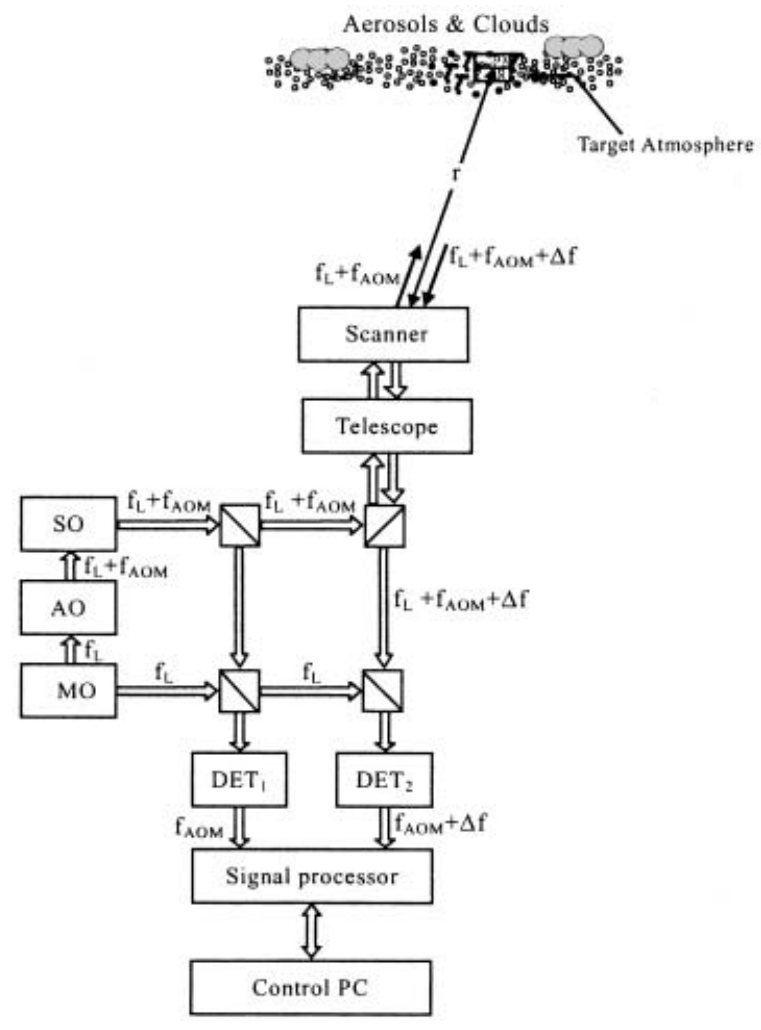

Fig. 2. Block diagram of a coherent Doppler lidar system.

Table 1. Specifications of a coherent Doppler lidar.

\begin{tabular}{ll}
\hline Transmitter & \\
Laser & Tm:YAG \\
Wavelength & $2.012 \mu \mathrm{m}$ \\
Pulse energy & $7 \mathrm{~mJ} / \mathrm{pulse}$ \\
Pulse width (FWHM) & $560 \mathrm{~ms}$ \\
Pulse Repetition & $100 \mathrm{~Hz}$ \\
Receiver & \\
Effective clear diameter $8 \mathrm{~cm}$ \\
Scan & Conical/Step and Stare \\
Elevation angle & $70^{\circ}$ \\
Wedge prism & Silicon $\left(8^{\circ}\right.$ wedge angle) \\
Pointing accuracy & $0.1^{\circ}$ \\
Detector & InGaAs \\
Data Processing & \\
Signal processing & $8 \mathrm{Bit} \mathrm{A} / \mathrm{D}$ conversion \\
Sampling frequency & $100 \mathrm{MHz}$ \\
Range resolution $\Delta r$ & $96 \mathrm{~m} \mathrm{per} 1$ range-gate \\
Vertical resolution $\Delta z$ & $90 \mathrm{~m}\left(=\Delta r \cdot\right.$ sin $\left.70^{\circ}\right)$ \\
\hline
\end{tabular}


$2.012 \mu \mathrm{m}$. The laser beam transmitted from the MO is passed through the acoustic-optical modulator (AOM). The modulator upshifts the frequency of the MO by $105 \mathrm{MHz}$. The frequency-shifted laser beam is then modematched and injected into the high-power Qswitched SO at a pulse repetition frequency of $100 \mathrm{~Hz}$. The laser pulse is transmitted into the atmosphere at an elevation angle of $70^{\circ}$ through the 8-cm-effective-diameter telescope and the scanning device. The backscattering by aerosol particles is more important than that by atmospheric molecules. The spectrum width of the backscattered signal is about $1 \mathrm{MHz}$. The molecule spectrum is much wider, on the gigahertz order. Therefore, the spectral density of atmospheric molecules is much lower than that of aerosol particles. Only the backscattered signal that is Doppler-shifted by moving aerosol particles is observed by the $2-\mu \mathrm{m}$ CDL system. A portion of the MO power is photomixed with the $\mathrm{SO}$ output on detector $\mathrm{DET}_{1}$ and with the backscattered signals on detector $\mathrm{DET}_{2}$. The backscattered signal $P(r)$ detected on detector $\mathrm{DET}_{2}$ is given by

$$
P(r)=K \cdot P_{0} \cdot \frac{1}{r^{2}} \cdot \frac{c}{2} \cdot \beta_{A}(r) \cdot T^{2}(r),
$$

where $P(r)$ is the received power at the detector, $P_{0}$ is the laser output power, $\beta_{A}(r)$ is the backscattering coefficient by aerosol particles, $r$ is the range from the CDL system to the target atmosphere, $T(r)$ is the atmospheric transmission, $c$ is the light velocity, and $K$ is a constant determined by several parameters (heterodyne efficiency, detector quantum efficiency, receiver area, optical efficiency, and so on).

The mixers (detectors) convert the frequencies of a laser pulse and the backscattered signals down to radio frequencies; i.e., an intermediate frequency (IF). This detection process is referred to as heterodyne detection. The heterodyne detection is operated under the shot noise limited condition where shot noise due to the portion of the MO power dominates all other noise by about $13 \mathrm{~dB}$. After amplification, filtering, and frequency-conversion, both outputs of each detector are digitized at a rate of $100 \mathrm{MHz}$ using 8-bit A/D converters (Signatec: VDA500Digitizer). The converted data are processed by a digital signal processor (Spectrum: Monaco) and the converted and processed data are then transferred to the host computer PC via VME bus. A 256-point fast Fourier transform (FFT) and a 64-point FFT are used to calculate the power spectrum of the laser pulse and that of the backscattered signal, respectively. After accumulating the power spectra for two or three thousand laser pulses and subtracting the noise power spectra obtained by averaging the power spectra at altitudes where only noise exists, the first moments of the power spectrum of the laser pulse and the backscattered signal are calculated as the mean IF frequencies (Doviak and Zrinć 1983). The Doppler-shifted frequency $\Delta f$ is then given as the difference between the mean IF frequencies.

The Doppler-shifted frequency $\Delta f(r)$ directly determines the line-of-sight (LOS) component $\left(V_{\mathrm{LOS}}\right)$ of the wind vector. The LOS component is obtained as

$$
V_{\mathrm{LOS}}(r)=\frac{c}{2 \cdot f_{L}} \cdot \Delta f(r),
$$

where $f_{L}$ is the laser frequency. At a laser wavelength $\lambda_{L}$ of $2.012 \mu \mathrm{m}$, a Doppler-shifted frequency $\Delta f(r)$ of $1 \mathrm{MHz}$ corresponds to a LOS component of about $1 \mathrm{~m} \cdot \mathrm{s}^{-1}$. The LOS component depends on the wind vector components, $u, v$, and $w$, and is given by

$$
\begin{aligned}
V_{\mathrm{LOS}}(z, \theta)= & u(z) \sin \theta \cos \phi+v(z) \cos \theta \cos \phi \\
& +w(z) \sin \phi,
\end{aligned}
$$

where $\theta$ is an azimuth angle from the north, $\phi$ is an elevation angle $\left(=70^{\circ}\right)$, and $z(=r \cdot \sin \phi)$ is an altitude above the CDL system. Figure 3 illustrates the principle of a ground-based conical scan. The LOS component obtained at the same altitude shows a sinusoidal curve as indicated in Fig. 3 when the horizontal wind velocity does not change at the same altitude of the target atmosphere. By making observations at several azimuth angles (at least three) and an elevation angle, one can obtain a wind vector with a velocity-azimuth display (VAD) technique (Browning and Wexler 1968; Caya and Zawadzki 1992). In this paper we observed LOS components at nine azimuth angles $\left(0^{\circ}\right.$, $\left.45^{\circ}, 90^{\circ}, 135^{\circ}, 180^{\circ}, 225^{\circ}, 270^{\circ}, 315^{\circ}, 360^{\circ}\right)$. We fitted a sinusoidal curve of Fig. 3 to the data through the least squares method to derive horizontal and vertical wind components. 

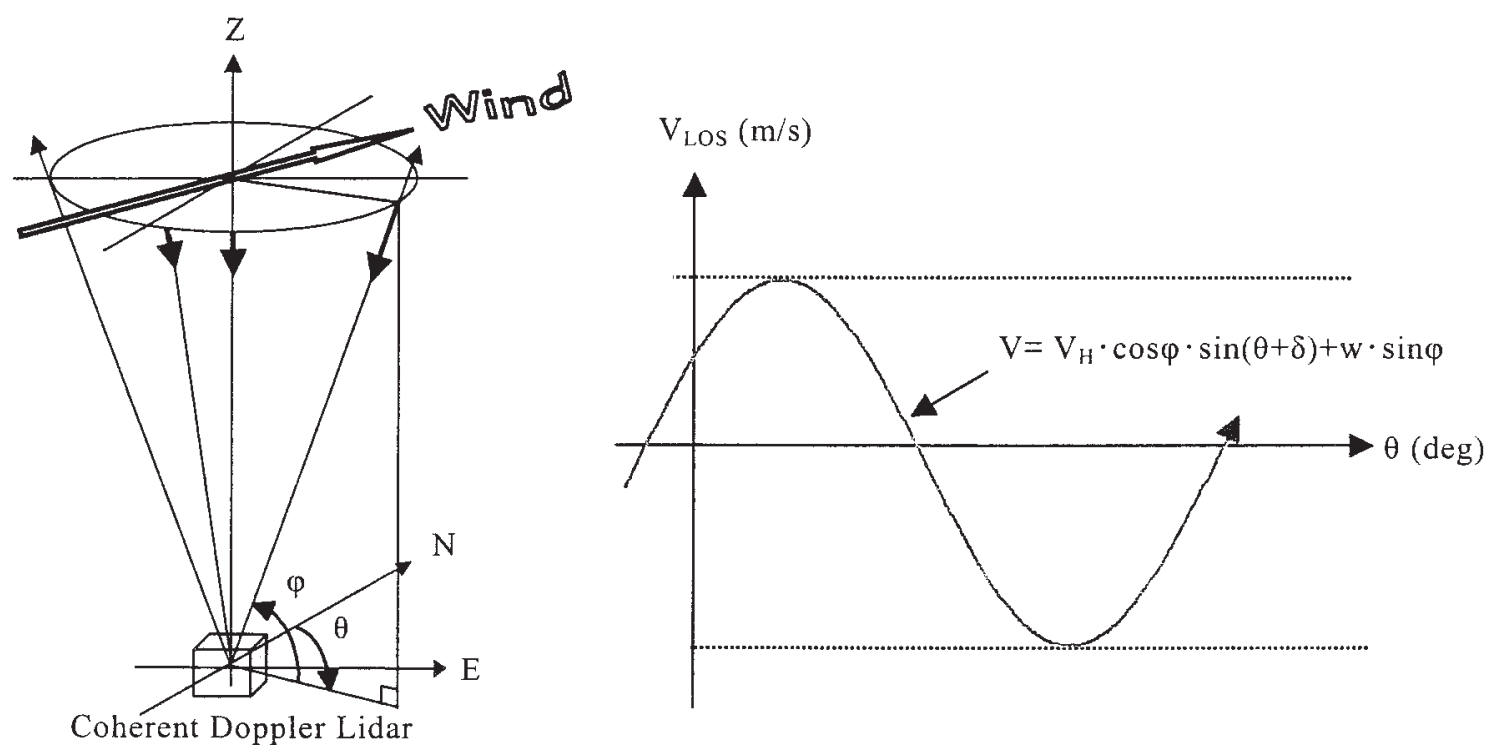

Fig. 3. Conceptual illustration of the VAD technique. $V_{H}$ is the horizontal wind velocity.

\subsection{Signal-to-noise ratio}

Figure 4 shows an illustration of the power spectra of the heterodyne beat signal. Backscattered signal and noise powers correspond to the hatched and non-hatched areas, respectively. In this paper, the signal-to-noise ratio $\mathrm{SNR}(r) \mathrm{dB}$ is defined as

$$
\operatorname{SNR}(r)=10 \cdot \log _{10}\left(\frac{\sum_{j=0}^{n} \sum_{i=i_{\text {peak }}-1}^{i_{\text {peak }}+1} p_{s, i, j}(r)}{\sum_{j=0}^{n} \sum_{i=0}^{31} p_{n, i, j}(r)}\right),
$$

where $p_{s, i, j}$ and $p_{n, i, j}$ are the power spectral density at the $i$-th frequency point of the backscattered signal and noise, respectively, $i_{\text {peak }}$ is the frequency point with the maximum power spectral density of the backscattered signal, and $n$ denotes the number of the laser pulse accumulation. We determined $p_{n, i, j}$ in the region $i_{\text {peak }-1}<i<i_{\text {peak }+1}$ by linear interpolation from other data points.

\section{Results and discussion}

The ground-based experiments were performed on September 3 and 4, 2002 at the NICT Wakkanai Radio Observatory. Figure 5 shows an example of the heterodyne beat signal of the laser pulse versus time, the power spectrum of the 256-point FFT laser pulse, and that

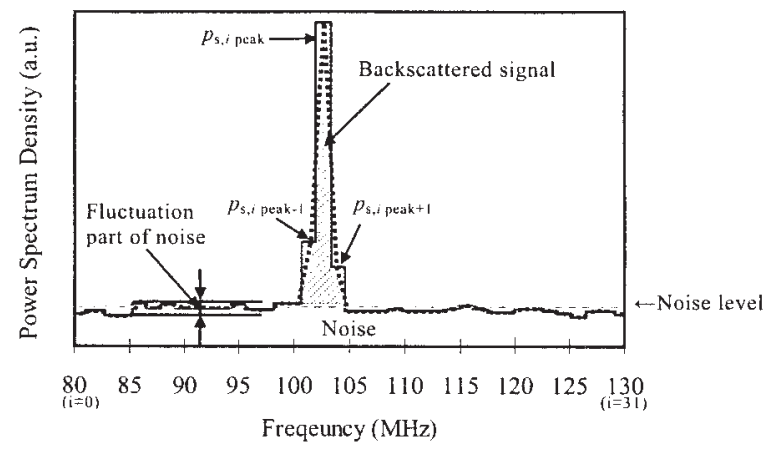

Fig. 4. Illustration of the position of the first moment estimates obtained using the FFT. The signal and noise parts of the spectrum are hatched and nonhatched, respectively. $i$ is the power spectrum number.

of the 64-point FFT signal backscattered at a range of $2 \mathrm{~km}$. The full width at half maximum (FWHM) of the laser pulse's power spectrum was about $1.2 \mathrm{MHz}$. The FWHM for the 64point FFT signal backscattered was about 1.8 MHz, but when we applied the 256-point FFT it was about $1.5 \mathrm{MHz}$ (not shown). The wider FWHM for the 64-point FFT backscattered signal was caused by wind turbulence (about 1.0 MHz, Frehlich 1997), lower FFT frequency resolution of the backscattered signal 

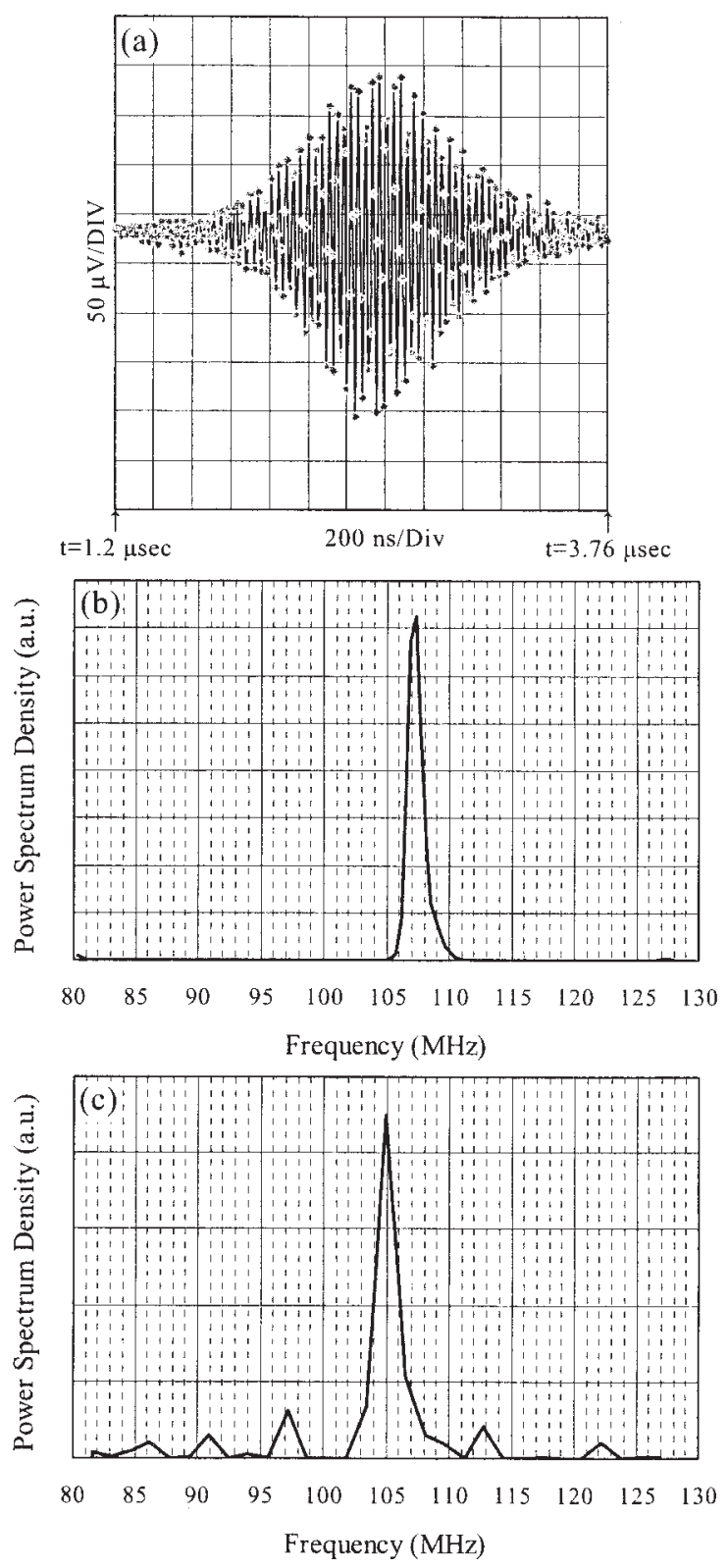

Fig. 5. (a) Heterodyne beat signal between the master oscillator and the transmitted laser pulse. The $t=0 \mu \mathrm{sec}$ is the ending of the Q-switch signal. (b) Sample power spectrum of the 256point FFT heterodyne beat signal shown in (a). (c) Sample power spectrum of the 64-point FFT beat signal between the master oscillator and the signal backscattered at a range of $2 \mathrm{~km}$. (about $0.8 \mathrm{MHz}$ ), wind shear, and Brownian motion of aerosol particles (about $0.1 \mathrm{MHz}$ ) (Michelangeli et al. 1972).

Figure 6 shows an example of nine sets of power spectra from 64-point FFT range-gated backscattered signals (thin lines). The rangegated number $i(=1-110)$ of power spectrum is shown on the right of each panel. (The gray thick lines show the power spectrum for a 256point FFT laser pulse.) Note that each power spectrum of the range-gated backscattered signals was rescaled by multiplying square the range, $r^{2}$, for convenience. The range-gated LOS components for each azimuth angle were obtained from the difference between the first moment of the power spectra of the laser pulse and that of the backscattered signals. Figures 7(a) and (b) show sets of nine LOS components calculated as the first moment of the power spectra of the backscattered signal shown in Fig. 6, and the signal-to-noise ratio corresponding to those LOS components calculated by using Eq. (4). Each pair of profiles obtained in opposite directions was mostly symmetrical with respect to the monitor position of the laser pulse; that is, corresponding to a LOS component of $0 \mathrm{~m} \cdot \mathrm{s}^{-1}$ because of the relatively low vertical velocities. Most LOS components obtained at the same altitude were in accordance with the sinusoidal curve of Eq. (3). Figure 7 indicates that the wrong LOS component (bad estimate) occur at altitudes higher than $8.5 \mathrm{~km}$, where the signal-to-noise ratio is lower than about $-24 \mathrm{~dB}$. Figure 8 shows the time variations in the signal-to-noise ratio profiles calculated by Eq. 4, and measured at an azimuth angle of $0^{\circ}$ on September 3 and 4 . The upper limit for reliable estimation depends on the atmospheric conditions and the CDL system obtained wind profiles at altitudes of up to $6 \mathrm{~km}$ to $8.5 \mathrm{~km}$ on those days. High-level clouds were easily visible to the human eye and may be the reason of the enhancement of the signalto-noise ratio at altitudes of $6 \mathrm{~km}$ to $8 \mathrm{~km}$. Because the aerosol particles in the atmosphere, however, were removed after the passage of typhoon 0215 , visibility for this period was high, that is, the atmospheric condition was rather poor in a sense of lidar sensitivity. It should be also noted that in summertime measurement precision becomes better in the middle and upper troposphere because of higher aerosol den- 

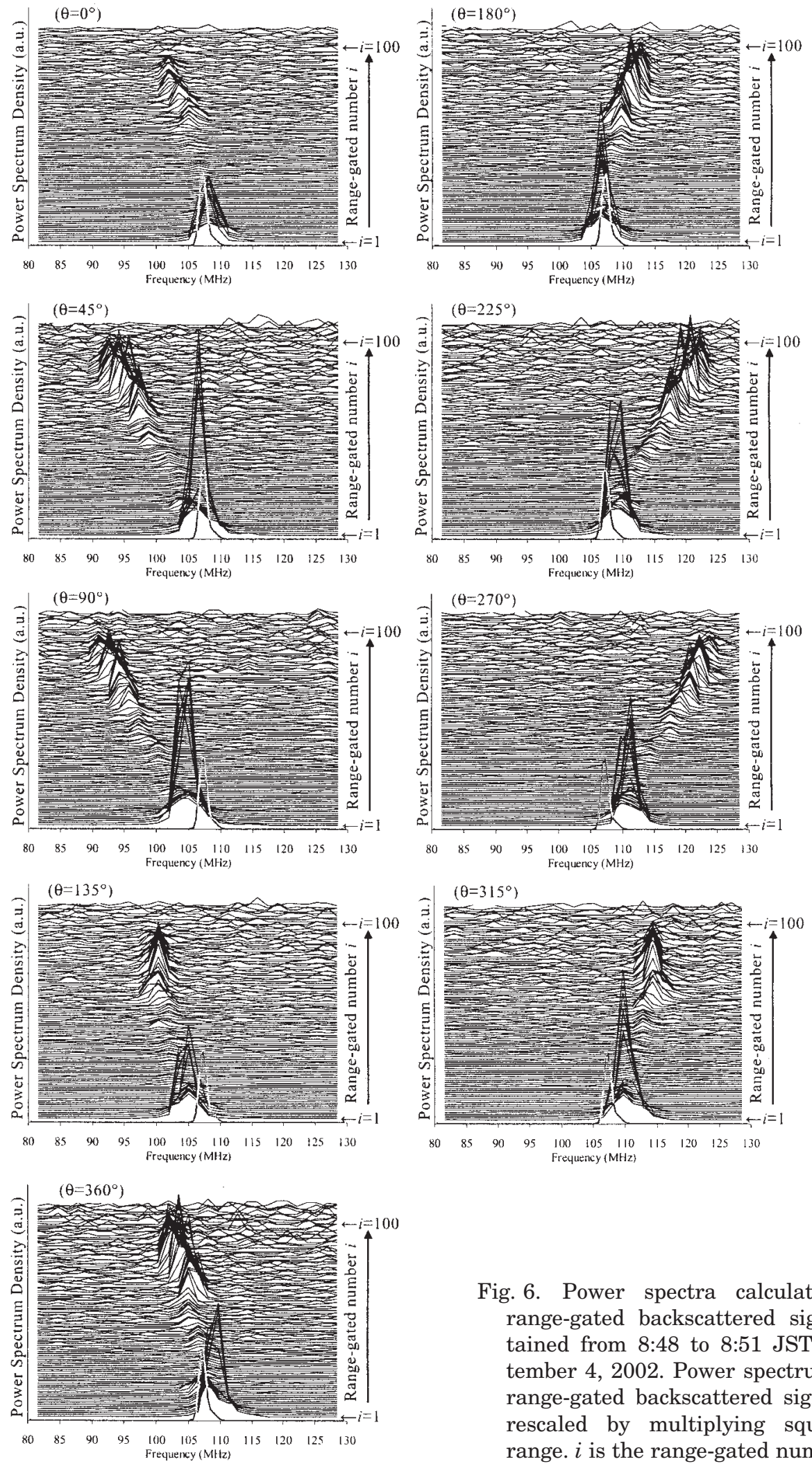

Fig. 6. Power spectra calculated from range-gated backscattered signals obtained from 8:48 to 8:51 JST on September 4, 2002. Power spectrum of the range-gated backscattered signals was rescaled by multiplying square the range. $i$ is the range-gated number. 

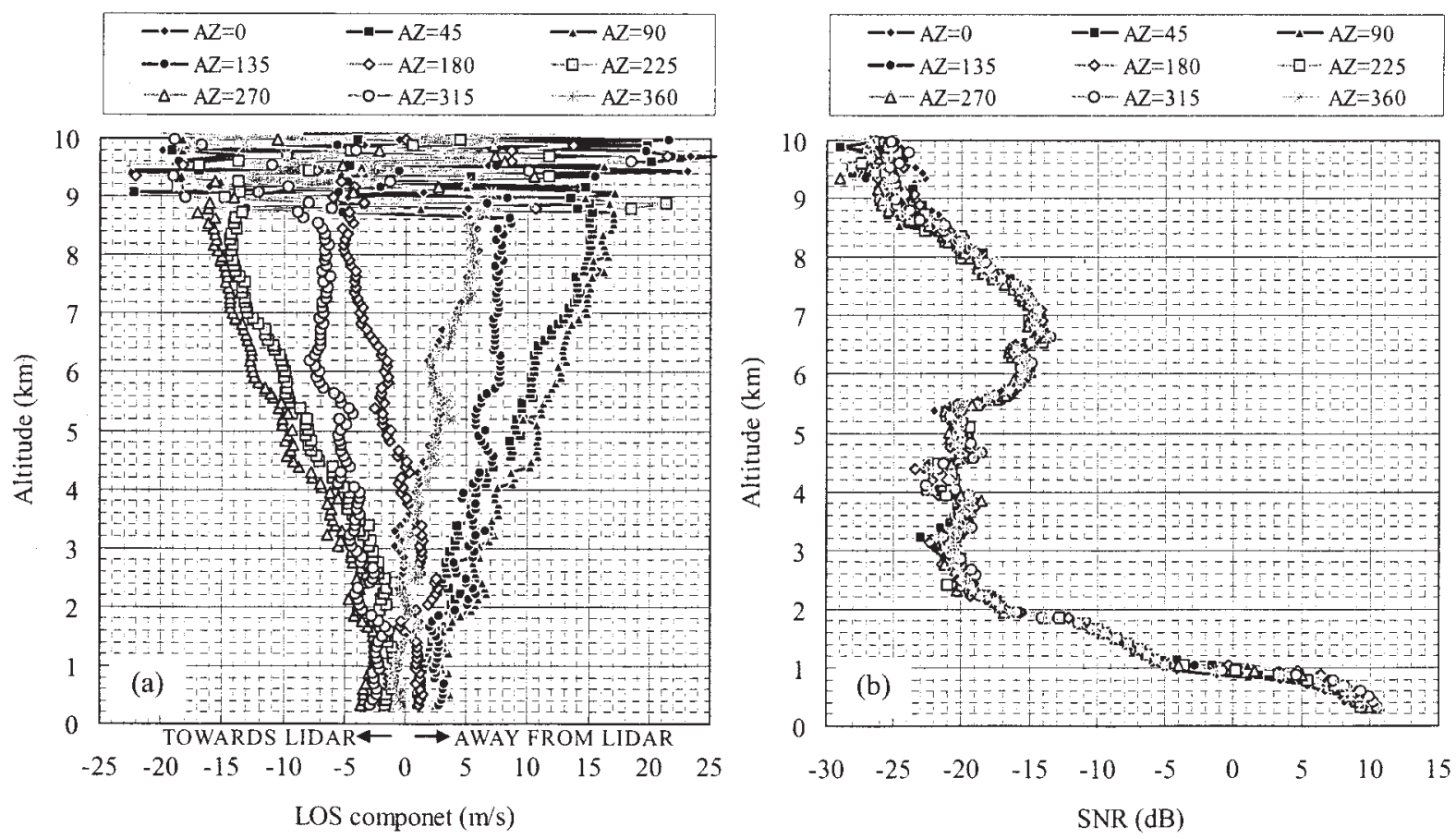

Fig. 7. (a) Nine LOS components calculated from the power spectra shown in Fig. 5. (b) Signal-tonoise ratio corresponding to the nine LOS components.

sity, but in wintertime, it could be significantly decreased in the middle troposphere.

Figure 9 shows the variation of the standard deviation of the LOS component as a function of laser pulse accumulation for various average signal-to-noise ratios. The standard deviation improves with the laser pulse accumulation under the conditions that the probability density function of the estimated Doppler-shifted frequency has a Gaussian profile and that the wind filed is not changing over the total accumulation time and in a target volume (Rye and Hardesty 1993; Frehlich and Yadlowky 1994; Frehlich et al. 1994). Though increasing the laser pulse accumulation causes improvement to the wind velocity estimate, the standard deviation appears to approach a constant value of 0.1 to $0.2 \mathrm{~m} \cdot \mathrm{s}^{-1}$ for the high signal-to-noise ratio in Fig. 9. The standard deviation does not necessarily improve with the laser pulse accumulation under the real atmospheric conditions.

Figures 10(a) through 10(h) show the relation between the signal-to-noise ratio calculated by Eq. (4) and the standard deviation of the LOS component observed by the CDL system at an azimuth angle of $0^{\circ}$ for various laser pulse accumulation. The standard deviation increases rapidly on a certain signal-to-noise ratio, which decreases approximately according to the square root of the laser pulse accumulation number. The low signal-to-noise ratio causes that the correct position of the backscatter signal is not obtained by finding the frequency point with the maximum of power spectrum density, that is, the wrong LOS component is produced. At the very low signal-to-noise ratio, the standard deviation is distributed around a value of $14.4 \mathrm{~m} \cdot \mathrm{s}^{-1}$ corresponding to the case of uniform probability density function indicated by Rye and Hardesty (1993) and Frehlich and Yadlowky (1994). Figures 10(a) through 10(h) also suggest that the standard deviation of the LOS component does not necessarily approach the Cramer-Rao bound (Levin 1965) under the real atmospheric conditions, which is the theoretical best performance.

Figure 11 shows examples of the wind profiles measured by the CDL system, the VHFR system, and the radiosonde. The black lines with squares show the wind profile derived 

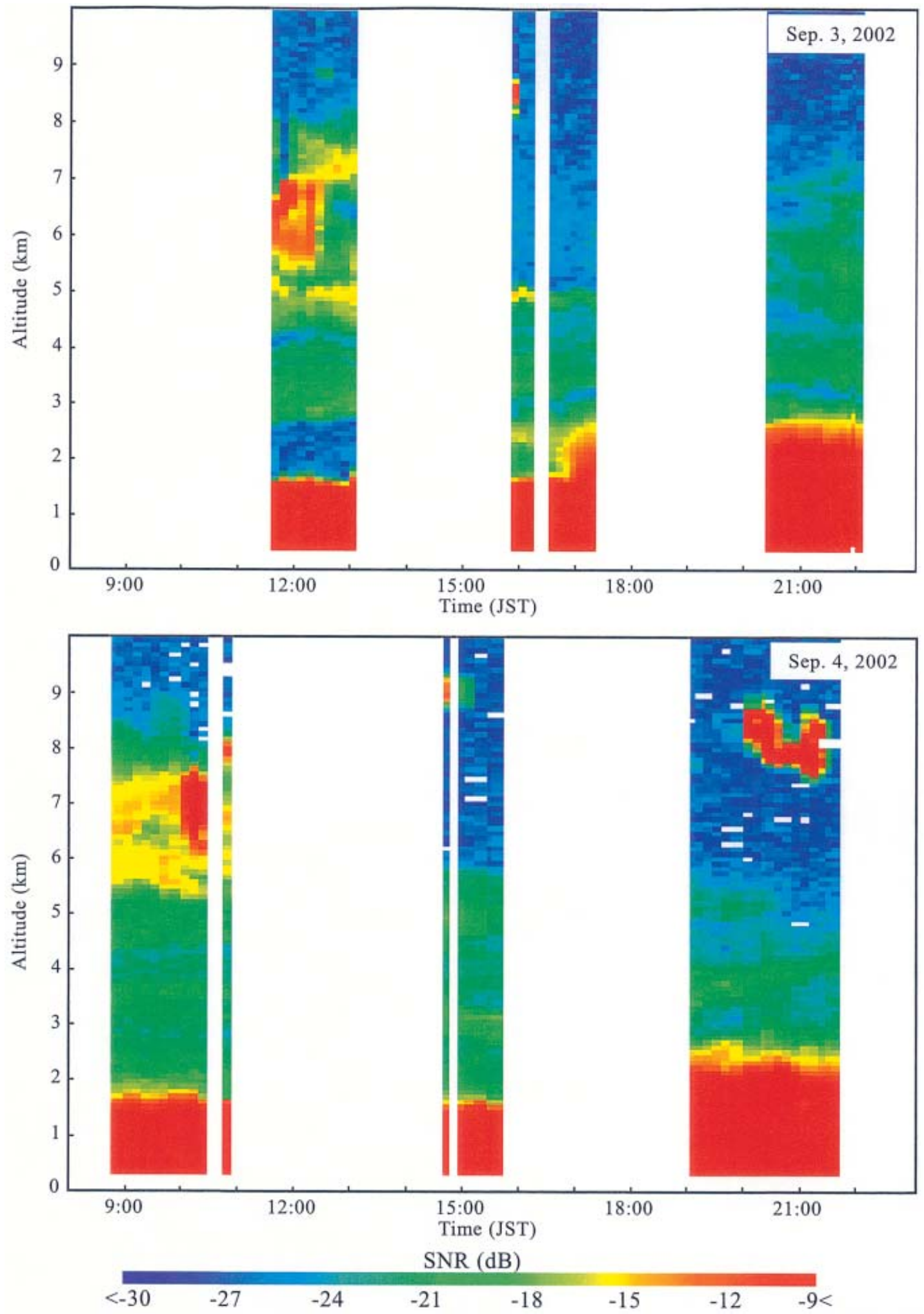

Fig. 8. Time variations in signal-to-noise ratio calculated by Eq. (4) and backscattered signals measured at the azimuth angle of $0^{\circ}$. 


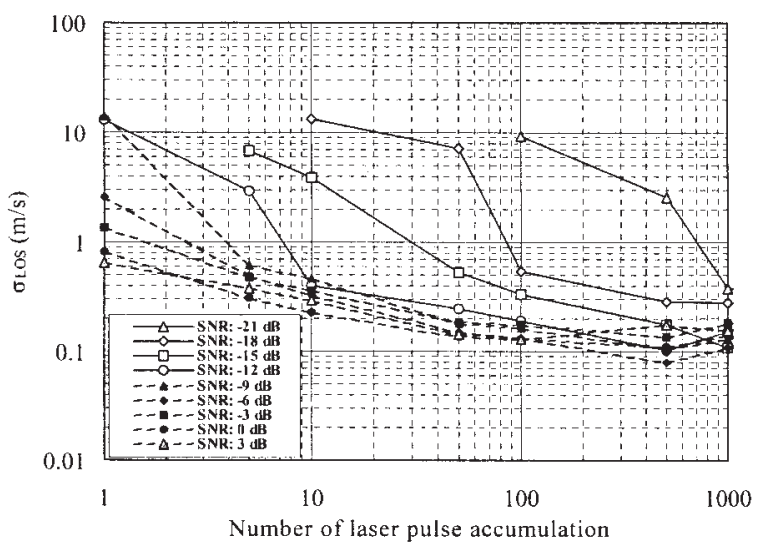

Fig. 9. Standard deviation $\sigma_{\mathrm{LOS}}$ of LOS component of wind velocity in the $N$ times of measurement for various signal-to-noise ratios.

from the CDL system and the VAD technique. Gray lines with circles and diamonds show the wind profiles from the radiosonde and the VHFR system, respectively. Since the wrong LOS component was produced at altitudes higher than $8.5 \mathrm{~km}$, as shown in Fig. 7(a), the reliable wind profile was not obtained at the altitudes. The horizontal wind profile measured by the CDL system agrees well with those obtained by other instruments. However, the horizontal wind velocities measured by the VHFR system were a little lower than those from the CDL system. The agreement between the CDL system and the radiosonde was better. A radiosonde was launched every 12, or 24 hours. While a radiosonde cannot obtain a wind profile with a high time resolution, the CDL system can measure a wind profile within 3 to 5 minutes. The CDL system can therefore continuously capture changes in wind profiles over time. In Fig. 11(c), although the pattern of the vertical wind profile obtained by the CDL system resembles that by the VHFR system, there is an apparent difference in both profiles. Vertical wind velocities were change around $0 \mathrm{~m} \cdot \mathrm{s}^{-1}$ in each measurement and we cannot find any tendency of the vertical motion in this experiment.

Figure 12 shows an example of the time variation in horizontal wind profiles observed by the CDL and VHFR systems. The interval between successive profiles was ten minutes.
The direction of an arrow indicates the wind direction. The lowest observable altitude with the CDL system was roughly $500 \mathrm{~m}$. The maximum altitude for reliable wind estimation was roughly $8.5 \mathrm{~km}$ and $6 \mathrm{~km}$, respectively. The signal-to-noise ratio in the CDL system depends on the aerosol density. The difference in the maximum observable altitudes was due to a change in aerosol density at higher altitudes, because the difference of extinction was small. The time variations of both horizontal wind profiles are similar. The vertical resolutions of the CDL and VHFR systems were $90 \mathrm{~m}$ and $600 \mathrm{~m}$, respectively and we can see wind structures with the high resolution by the CDL system. For example, the wind profiles observed by the CDL system from 19:00 to 22:00 JST on September 4 show more detailed changes in height than those provided by the VHFR system, though the difference between the wind profiles observed by the CDL and VHFR systems may also attributed to the velocity underestimation in the VHFR system as described later. We can see from Fig. 12 that the CDL system captures strong vertical wind shear and detailed air flow.

In Figs. 13(a) and (b) we compare the wind velocities and directions obtained by the radiosondes and thirty-minute average results of the CDL system during four periods (20:30-21:00 JST on September 3, and 8:30-9:00, 14:3015:00, and 20:30-21:00 JST on September 4). The dashed-gray-lines show the expected 1:1 relationship, and the black lines are linear fitting lines with intercepts of 0 . The slopes of the horizontal wind velocity and wind direction were close to 1 . That is, the wind vectors obtained by the CDL system agreed well with those from the radiosondes. It should be emphasized that the CDL system can obtain the wind velocity correctly over a wide range of wind velocities. Figures 13(c) and (d) show the same sort of scatter plots, in this case comparing the CDL system and the VHFR system ten-minute average results during six periods (11:30-13:00, 15:30-17:00, and 20:30-22:00 JST on September 3, and 8:30-11:00, 14:3016:00, and 19:00-22:00 JST on September 4). The slope of the line comparing the horizontal wind velocities was less than 1 , indicating that the average wind velocities obtained by the VHFR system were lower than those obtained 

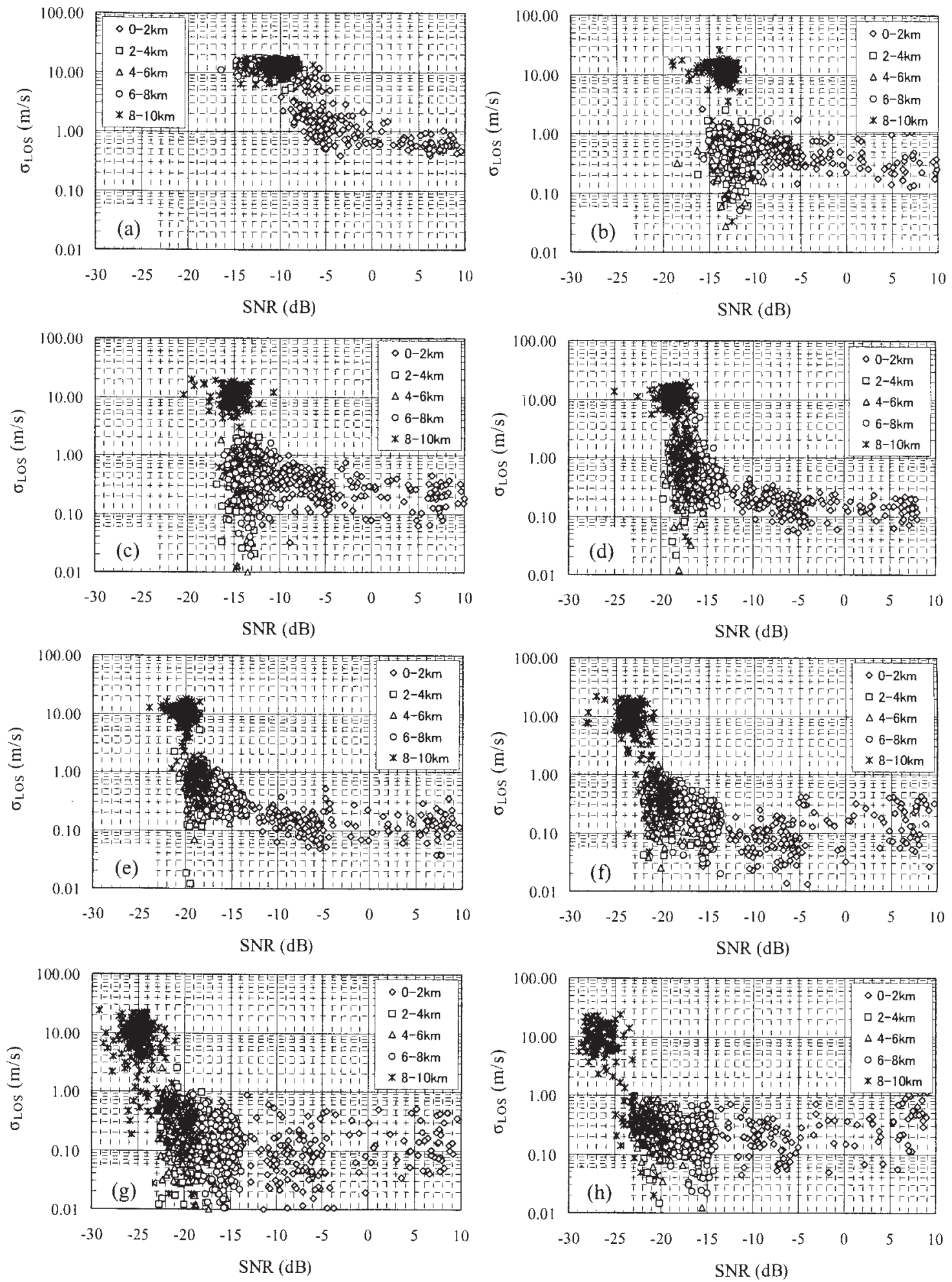

Fig. 10. Standard deviation $\sigma_{\operatorname{LOS}}$ of LOS component of wind velocity as a function of the signal-tonoise ratio SNR for various laser pulse accumulation: (a) 1 pulse, (b) 5 pulses, (c) 10 pulses, (d) 50 pulses, (e) 100 pulses, (f) 500 pulses, (g) 1000 pulses, and (h) 2000 pulses. The symbols show the

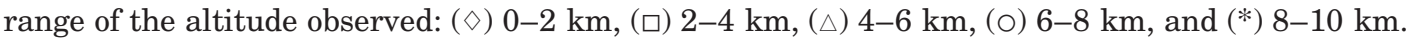



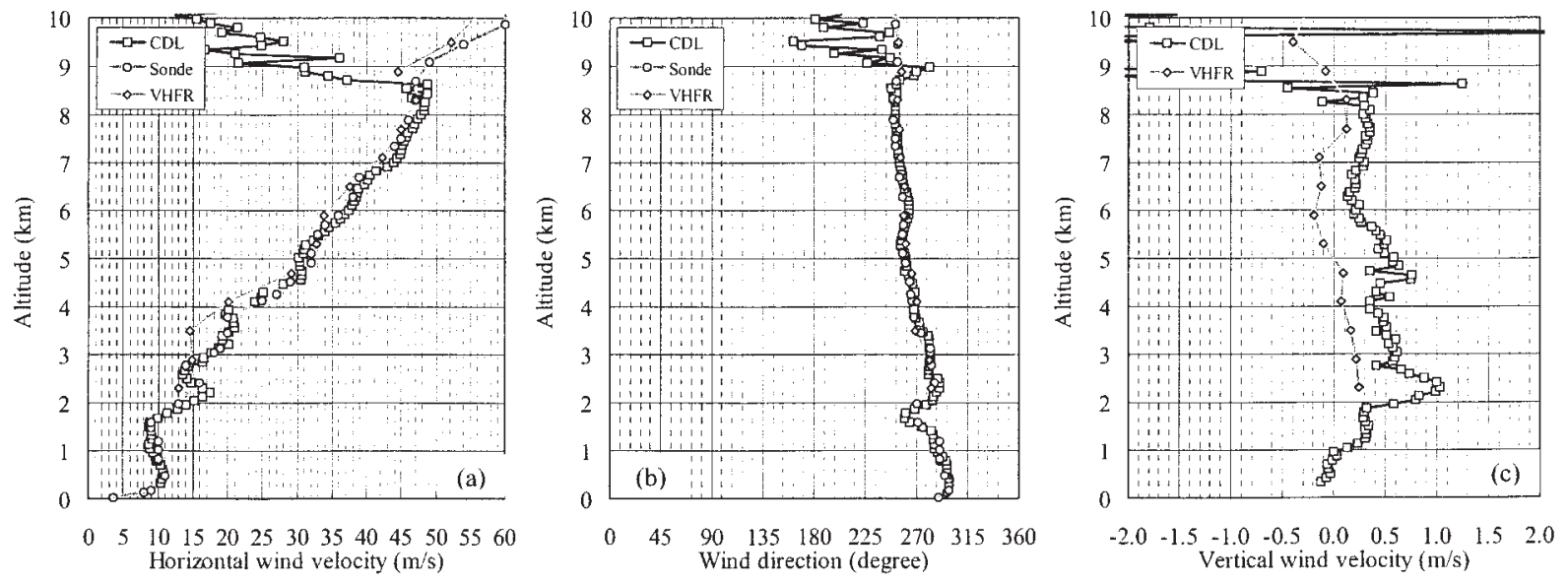

Fig. 11. (a) Horizontal wind velocity, (b) wind direction, and (c) vertical wind velocity measured by the coherent Doppler lidar system (CDL), the VHF radar system (VHFR) from 8:48 to 8:51 JST on September 4, 2002, and a radiosonde (RS) launched at 8:30 JST.

by the CDL system. The results also indicated differences in the horizontal wind velocity between the radiosondes and the VHFR system. Full correlation analysis (FCA) was applied in the VHFR system to obtain wind profiles, and this analysis can produce velocity underestimations (Reid 1996; Holdsworth and Reid 1997). The quality of data obtained from the VHFR system will be improved in the future through use of a revised computational algorithm.

The statistical results of bias, standard deviation, relative standard deviation, and correlation coefficient for all measurements were calculated as defined by Chintawongvanich et al. (1989). A summary of the results from the intercomparison of wind profiling with the CDL system, radiosondes, and the VHFR system is given in Table 2. The differences in horizontal wind velocity and wind direction between the CDL system and the radiosonde were $0.2 \mathrm{~m} \cdot \mathrm{s}^{-1}$ and $1.4^{\circ}$, respectively. Since the minimum scale of the radiosonde when measuring wind velocity is $1 \mathrm{~m} \cdot \mathrm{s}^{-1}$, the velocity difference between the CDL system and the radiosonde was almost negligible. The difference in the wind direction was due to an inaccuracy in the CDL system alignment during the setup. There were high correlation coefficients between the CDL system and the radiosonde. The differences in horizontal wind velocity and wind direction between the CDL system and the VHFR system were $-2.1 \mathrm{~m} \cdot \mathrm{s}^{-1}$ (due to the underestimation of wind velocity in the VHR radar as explained above) and $-0.9^{\circ}$. Our results support previously obtained statistical results (Murayama 2003). It can be considered that the reasons why wind profiles observed with the radiosonde agreed with those from the CDL system better than from the VHFR system are the velocity underestimation produced by FCA, and the measurement bias and vertical resolution between the radiosonde and the VHFR system.

\section{Conclusions}

We performed ground-based experiments to examine the effectiveness of wind measurement using an eye-safe coherent Doppler lidar system at Wakkanai, Hokkaido on September 3 and 4, 2002. Experimental results from the coherent Doppler lidar system were compared with those obtained from radiosondes and the VHFR system. Wind profiles observed with the coherent Doppler lidar system were in good agreement with those from radiosondes. We investigated the relations between results from the coherent Doppler lidar system and other systems statistically. The systematic differences between the coherent Doppler lidar system observations and the radiosonde and the VHFR system observations were $0.2 \mathrm{~m} \cdot \mathrm{s}^{-1}$ and $1.4^{\circ}$, and $-2.1 \mathrm{~m} \cdot \mathrm{s}^{-1}$ and $-0.9^{\circ}$, respectively. The coherent Doppler lidar system can continuously measure a wind structure in more 

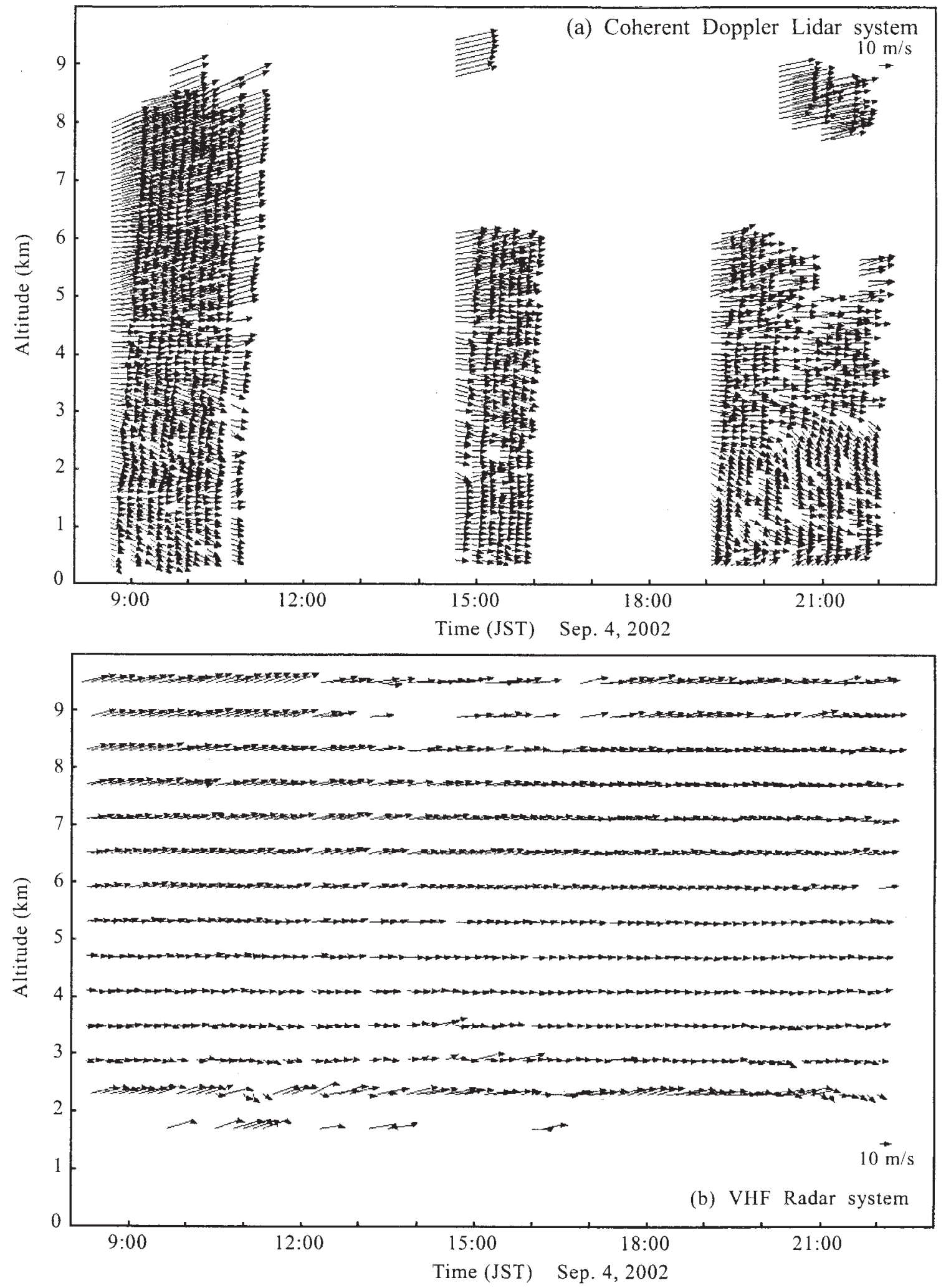

Fig. 12. Time variations in horizontal wind vector: (upper panel) coherent Doppler lidar system, and (lower panel) VHF radar system. 

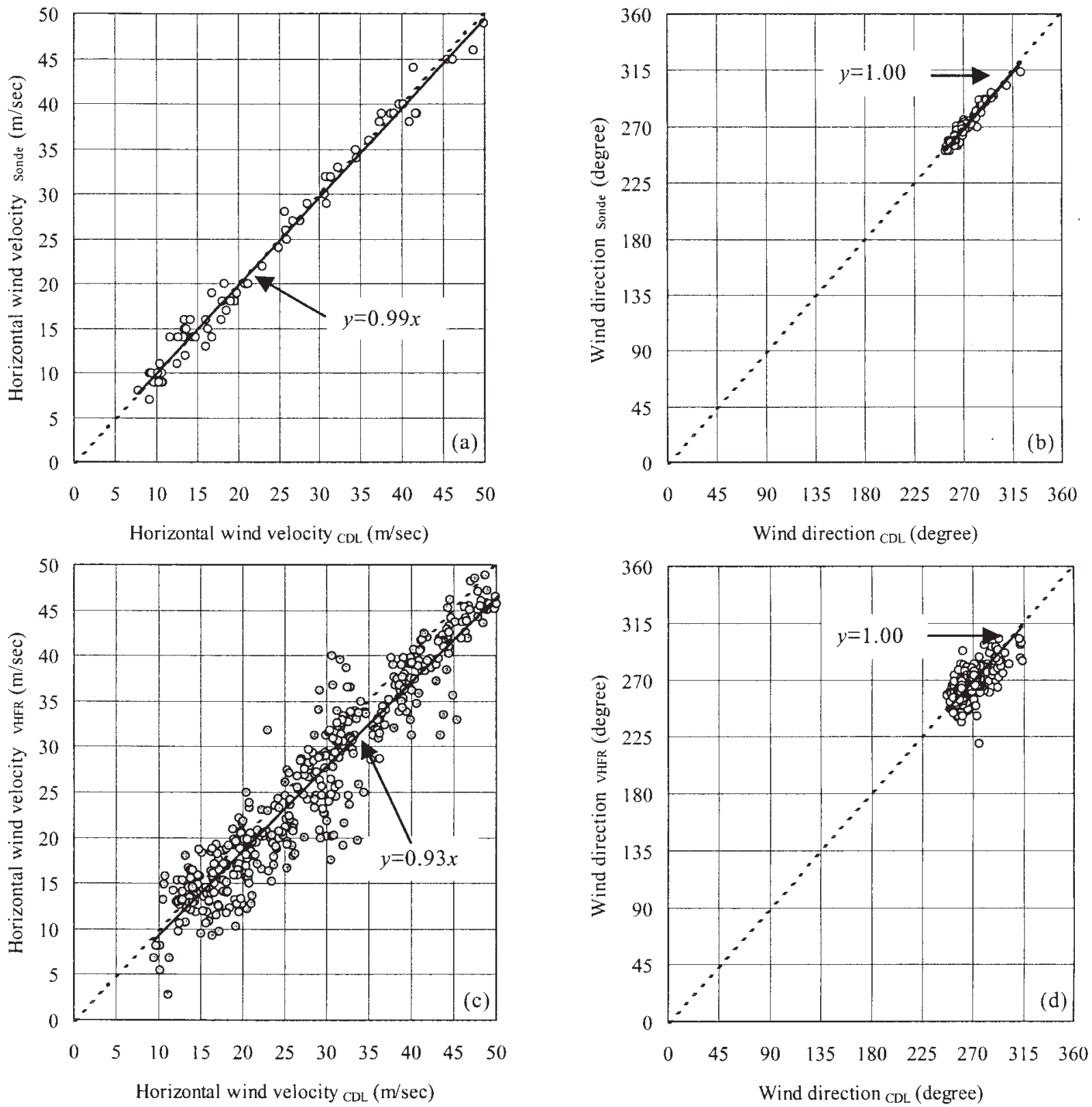

Fig. 13. Comparison of horizontal wind velocity and wind direction: (a) and (b) the coherent Doppler lidar system and radiosondes, and (c) and (d) the coherent Doppler lidar system and the VHF radar system. The 1:1 line is overplotted, and the slope of the linearization with an intercept of 0 is shown.

detail than is possible with other instruments. The ground-based results showed that the standard deviation of the LOS component measured with the laser pulse accumulation approached a constant value of 0.1 to $0.2 \mathrm{~m} \cdot \mathrm{s}^{-1}$ under the real atmospheric conditions, that is, the standard deviation does not necessarily im- prove with the laser pulse accumulation for the high signal-to-noise ratio. The lower limit of the signal-to-noise ratio for reliable estimates decreases with the laser pulse accumulation. The ground-based results convinced us to approve use of the system for airborne applications. The accuracy and reliability of wind pro- 
Table 2. Statistical Comparison of horizontal wind velocity and wind direction observed with a CDL system, radiosondes (RS), and a VHFR system.

\begin{tabular}{|c|c|c|c|c|}
\hline & \multicolumn{2}{|c|}{ CDL and Sonde } & \multicolumn{2}{|c|}{$\begin{array}{l}\text { CDL and } \\
\text { VHF radar }\end{array}$} \\
\hline & $\begin{array}{l}\mathrm{HWV} \\
(\mathrm{m} / \mathrm{s})\end{array}$ & $\begin{array}{c}\text { WD } \\
\text { (degree) }\end{array}$ & $\begin{array}{l}\mathrm{HWV} \\
(\mathrm{m} / \mathrm{s})\end{array}$ & $\begin{array}{c}\text { WD } \\
\text { (degree) }\end{array}$ \\
\hline $\begin{array}{l}\text { Number of } \\
\text { samples }\end{array}$ & \multicolumn{2}{|r|}{81} & \multicolumn{2}{|c|}{440} \\
\hline Sample bias & 0.2 & 1.4 & -2.1 & -0.9 \\
\hline $\begin{array}{l}\text { Standard } \\
\text { deviation }\end{array}$ & 1.4 & 3.5 & 3.4 & 8.3 \\
\hline $\begin{array}{l}\text { Relative } \\
\text { standard } \\
\text { deviation }(\%)\end{array}$ & 6.1 & 1.3 & 12.7 & 3.1 \\
\hline $\begin{array}{l}\text { Coefficient of } \\
\text { correlation }\end{array}$ & 0.99 & 0.97 & 0.95 & 0.61 \\
\hline
\end{tabular}

HWV: horizontal wind velocity

WD: wind direction

files obtained by the coherent Doppler lidar system depend on the concentration of aerosol particles, and the frequency stability and output energy of the transmitted laser. We confirmed that the coherent Doppler lidar system can measure detailed atmospheric flow that changes within a short time. Our results indicated that the coherent Doppler lidar system is useful not only for observing local and mesoscale wind fields, but also for capturing the signs of a changeable atmospheric flow.

\section{Acknowledgments}

We are deeply indebted to the Wakkanai local meteorological observatory for providing the meteorological radiosonde data. We would like to thank the referees for helpful comments.

\section{References}

Atlas, R., 1997: Atmospheric observations and experiments to assess their usefulness in data assimilation. J. Meteor. Soc. Japan, 75, 111130 .

Baker, W.E. et al., 1995: Lidar-measured winds from space: a key component for weather and climate prediction. Bull. Amer. Meteor. Soc., 76, 869-888.

Bibro, J., G. Fitchtl, D. Fitzjarrald, and M. Krause, 1984: Airborne Doppler lidar wind field mea- surements. Bull. Amer. Meteor. Soc., 65, 348359.

Browning, R.A. and R. Wexler, 1968: The determination of kinematic properties of a wind field using Doppler radar. J. Appl. Meteor., 7, 105113.

Caya, D. and I. Zawadzki, 1992: VAD analysis of nonlinear wind fields. J. Atmos. Oceanic Technol., 9, 575-587.

Chintawongvanich, P., R. Olsen, and C.A. Biltoft, 1989: Intercomparison of wind measurements from two acoustic Doppler sodars, a laser Doppler lidar, and in situ sensors. J. Atmos. Oceanic Technol., 6, 785-797.

Cohn, S. and W.M. Angevine, 2000: Boundary layer height and entrainment zone thickness measured by lidar and wind-profiling radars. $J$. Appl. Meteor., 39, 1233-1247.

Doviak, R.J. and D.S. Zrnić, 1984: Doppler Radar and Weather Observations. Academic Press INC., 81-87 and 94-113.

Flesia, C., C.L. Korb, and C. Hirt, 2000: Double-edge molecular measurements of lidar wind profiles at 355-nm. Opt. Lett., 25, 1466-1468.

Frehlich, R., 1997: Effects of wind turbulence on coherent Doppler lidar performance. J. Atmos. Oceanic Technol., 14, 54-75.

_ and M.J. Yadlowky, 1994: Performance of mean-frequency estimators for Doppler Radar and lidar. J. Atmos. Oceanic Technol., 11, 1217-1230.

—, S.M. Hannon, and S.W. Henderson, 1994: Performance of a $2-\mu \mathrm{m}$ coherent Doppler lidar for wind measurements. J. Atmos. Oceanic Technol., 11, 1517-1528.

Gentry, B.M., H. Chen, and S.X. Li, 2000: Wind measurements with 355-nm molecular Doppler lidar. Opt. Lett., 24, 1231-1233.

Grund, C.D., R.M. Banta, J.L. George, J.N. Howell, M.J. Post, R.A. Richter, and A.M. Weickmann, 2001: High-resolution Doppler lidar for boundary layer and cloud research. J. Atmos. Oceanic Technol., 18, 376-393.

Henderson, S.W., P.J.M. Suni, C.P. Hale, S.M. Hannon, J.R. Magee, D.L. Bruns, and E.H. Yuen, 1993: Coherent laser radar at $2.1 \mu \mathrm{m}$ using solid-state lasers. IEEE Trans. Geosci. Remote Sens., 31, 4-15.

and K. Ota, 1997: Recent improvements in eyesafe, solid-state and coherent laser radar technology. Rev. Laser. Eng., 25, 19-24.

Holdsworth, D.A. and I.M. Reid, 1997: An investigation of biases in the full correlation analysis technique. Adv. Space Res., 20, 1269-1272.

Igarashi, K., M. Ikeda, R. Yamazaki, H. Kato, I. Iwamoto, and Y. Saito, 2000: A new atmospheric sounding radar system at Wakkanai 
(45 N, 141 E), Japan for the MVL (Multimedia Virtual Laboratory) experiment. Proc. of the Fifth International Symposium on Tropospheric Profiling, 77-79.

Itabe, T., K. Mizuitani, M. Ishizu, and K. Asai, 2001: ISS/JEM-borne coherent Doppler lidar program to measure the wind from space. Proc. of Society of Photo-Optical Instrumentation Engineering, 4153, 412-419.

Ishii, S., K. Mizuitani, M. Sasano, T. Itabe, and K. Asai, 2002: Coherent Doppler Lidar System for Airborne Measurement: a Ground-based Experiment of Atmospheric Wind Profiling. Proc. of Society of Photo-Optical Instrumentation Engineering, 4893, 480-487.

Kavaya, M.J., S.W. Henderson, J.R. Magee, C.P. Hale, and R.M. Huffaker, 1989: Remote wind profiling with a solid-state Nd:YAG coherent laser systems. Opt. Lett., 14, 776-778.

Levin, J.M., 1965: Power Spectrum Parameter Estimation. IEEE Trans. Inf. Theory, IT-11, 100107.

Murayama, Y., 2003: National Institute of Information and Communications Technology, Koganei, Tokyo (personal communication).

Michelangeli, G.B., F. Congeduti, and G. Fiocco, 1972: Measurement of aerosol motion and wind velocity in the lower troposphere by Doppler optical radar. J. Atmos. Sci., 23, 2510-2517.

Post, M.J. and R.E. Cupp, 1992: $\mathrm{CO}_{2}$ Lidar backscatter profiles over Hawaii during fall 1988. Appl. Opt., 31, 4590-4599.

Reid, I.M., 1996: On the measurement of gravity waves, tides and mean winds in the low and middle latitude mesosphere and thermosphere with MF radar. Adv. Space Res., 18, 131-140.

Rohaly, G.D. and T.N. Krishinamurti, 1993: An ob- serving system simulation experiment for the laser atmospheric wind sounder (LAWS). $J$. Appl. Meteor., 32, 528-532.

Rothermel, J., D.R. Cutten, R.M. Hardesty, R.T. Menzies, J.N. Howell, S.C. Johnson, D.M. Tratt, L.D. Olivier, and R.M. Bant, 1998: The multi-center airborne coherent atmospheric wind sensor. Bull. Amer. Meteor. Soc., 79, 581599 .

Rye, B.J. and R.M. Hardesty, 1993: Discrete spectral peak estimation in incoherent backscatter heterodyne lidar I: Spectral accumulation and the Cramer-Rao lower bound. IEEE Trans. Geosci. Remote Sens., 31, 16-27.

Shibata, T., M. Ishizu, and T. Itabe, 1991: Coherent Doppler lidar using a hybrid $\mathrm{CO}_{2}$ laser with a low pressure gain section below the threshold. J. Meteor. Soc. Japan, 69, 413-417.

Souprayen, C., A. Garnier, A. Hertzog, A. Hauchecorne, and J. Porteneuve, 1999: Rayleigh-Mie Doppler wind lidar for atmospheric measurements. I. Instrumental setup, validation, and first climatological results. Appl. Opt., 38, 2410-2421.

Targ, R.B., C. Steakley, J.G. Hawley, L.L. Ames, P. Forney, D. Swanson, R. Stone, R.G. Otto, V. Zarifis, P. Brockman, R.S. Calloway, S.H. Klein, and P.A. Robinson, 1996: Coherent lidar airborne wind sensor II: flight-test results at 2 and $10 \mu \mathrm{m}$. Appl. Opt., 36, 7117-7127.

Werner, Ch., P.H. Flamant, O. Reitebuch, F. Kopp, J. Streicher, S. Rahm, E. Nagel, M. Klier, H. Herrmann, C. Loth, P. Delville, P. Drobinski, B. Romand, C. Boitel, D. Oh, M. Lopez, M. Meissonnier, D. Bruneau, and A. Dabas, 2001: Wind infrared Doppler lidar instrument. Opt. Eng., 40, 115-125. 